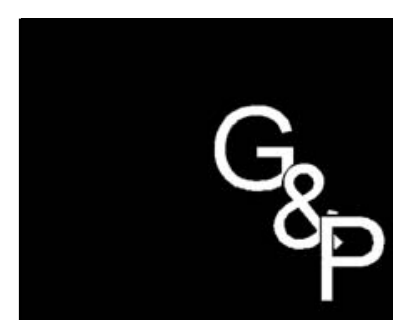

GESTÃO

$\stackrel{\text { \& }}{\text { PRODUÇÃO }}$

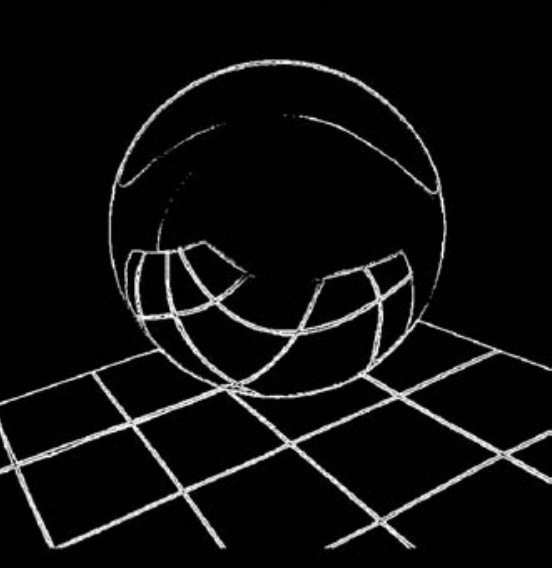

v.8, n.2, p.139-159, ago. 2001

\section{UM MODELO BASEADO EM PROGRAMAÇÃO LINEAR E PROGRAMAÇÃO DE METAS PARA \\ ANÁLISE DE UM SISTEMA DE PRODUÇÃO E DISTRIBUIÇÃO DE SUCO CONCENTRADO CONGELADO DE LARANJA}

\title{
Resumo
}

Neste trabalho apresenta-se um modelo baseado em programação linear e programação de metas para apoiar decisões no processo de mistura e na distribuição de suco concentrado congelado de laranja. Explora-se a importância das decisões do processo de mistura para a análise da logística de distribuição do suco de laranja, além das decisões de transporte e armazenagem. O modelo utiliza conceitos conhecidos da literatura de problemas de mistura e planejamento da produção com múltiplos produtos, estágios e períodos, e foi resolvido por meio da linguagem de modelagem GAMS (General Algebraic Modeling System). Um estudo de caso foi realizado numa empresa de suco de laranja localizada no interior do estado de São Paulo, e os resultados preliminares obtidos são promissores.

Palavras-chave: programação linear, programação de metas, processo de mistura, logística de distribuição, suco de laranja, planejamento da produção com múltiplos produtos, estágios e períodos.

\section{Introdução}

$\mathrm{N}^{2}$ a indústria de processamento de suco de aranja, a produção de sucos concentrados congelados (produtos finais), a partir das variedades de laranja (matérias-primas) disponíveis no mercado, envolve a análise de uma grande quantidade de informações para que se obtenha uma otimização da utilização dos recursos disponíveis. Em certos casos, a coordenação das atividades de produção, transporte e estocagem de produtos intermediários (bases para produção 
de sucos) e finais (sucos demandados) torna-se importante principalmente por causa da combinação da sazonalidade gerada pelas matérias-primas (variedades de laranja), e da relativa estabilidade da demanda dos produtos (neste estudo tal demanda é determinada pelo embarque periódico dos produtos num navio).

O presente trabalho apresenta um modelo baseado em programação linear e programação de metas (goal programming) para apoiar decisões táticas e operacionais no processo de mistura de bases para produção de sucos, e na distribuição (transporte e armazenagem) dos sucos produzidos. Explora-se a importância das decisões do processo de mistura das bases para a análise da logística de distribuição dos sucos produzidos. Conforme é discutido na próxima seção, o Brasil é o maior produtor e exportador mundial de suco concentrado congelado de laranja, o que evidencia a importância de pesquisas para melhorar o desempenho dos sistemas de produção e distribuição deste setor.

Em geral, o processo de otimização da distribuição do suco concentrado congelado de laranja envolve minimizar os custos de distribuição, o que resulta em maximizar a utilização do sistema de distribuição de suco a granel, uma vez que este é mais econômico do que o sistema de distribuição de suco em tambores (PINTO, 1996). Na empresa estudada no presente trabalho também se procura minimizar custos de mistura de bases e desvios de alguns objetivos secundários, tais como obter determinadas especificações para os produtos acabados, atendendo metas de qualidade. Tal otimização é feita na empresa com o auxílio de um simulador desenvolvido numa planilha eletrônica (software Lotus).

Basicamente, um modelo para apoiar as decisões de curto e médio prazo de distribuição de suco deve responder questões como: quanto, quando, como (granel ou tambor) e para onde transportar e estocar o suco produzido, respeitando datas de embarque do navio e restrições de capacidade de transporte e estocagem, isto tudo ao menor custo de transporte e estocagem possível. Para responder tais questões, o modelo também deve considerar as decisões de mistura de bases para produzir os sucos, como por exemplo quanto usar de cada base para produzir cada suco. Se a capacidade de estocagem a granel esgotar, pode-se decidir misturar bases para produzir e armazenar sucos em tambores. Neste trabalho apresenta-se um modelo linear para apoiar tais decisões, que considera custos de produção e distribuição, e utiliza conceitos conhecidos da literatura de problemas de mistura e planejamento da produção com múltiplos produtos, estágios e períodos. Para resolvê-lo, utiliza-se a linguagem de modelagem GAMS (General Algebraic Modeling System) (BROOKE et al., 1992).

$\mathrm{O}$ trabalho foi conduzido na unidade industrial de Matão-SP da Citrovita, porém, os pontos abordados neste estudo de caso também se aplicam a outras empresas do setor. O trabalho está organizado da seguinte maneira: na próxima seção apresenta-se uma breve descrição da indústria de suco de laranja e dos processos de mistura e distribuição. Na seção 3 propõe-se inicialmente um modelo de programação linear para tratar o problema minimizando os custos de mistura e distribuição e, em seguida, um modelo de programação de metas considerando também alguns objetivos secundários. $\mathrm{Na}$ seção 4 analisa-se os resultados computacionais obtidos com os modelos, ao serem aplicados numa situação simplificada do estudo de caso (devido à indisponibilidade de dados e para proteger interesses da empresa). Finalmente, na seção 5 conclui-se o trabalho e discute-se perspectivas para pesquisa futura.

\section{Descrição do Problema}

\subsection{A indústria de suco de laranja}

Conforme VIEGAS et al. (1983), o desenvolvimento da indústria de suco de laranja se deu nos EUA na década de 30, devido ao aumento do consumo do produto. As pesquisas mostraram que uma forma de incrementar o consumo de suco de laranja seria substituir a 
fruta, cujo consumo médio diário era de meia laranja por pessoa, pelo suco, pois, para produzir um copo de suco, utiliza-se de três a quatro laranjas. $\mathrm{Na}$ época, desenvolveu-se um programa para demonstrar as qualidades nutritivas da laranja e também houve o lançamento dos espremedores de fruta, o que facilitou a produção de sucos em bares, restaurantes e residências. Assim, no final da década de 30, $90 \%$ das famílias norte-americanas já consumiam suco de laranja cotidianamente.

Em 1944 teve início a comercialização do suco concentrado congelado de laranja. A princípio, o governo dos EUA incentivou a indústria comprando o produto para ser utilizado pelas Forças Armadas, para programas de alimentação escolar e de auxílio aos países aliados durante a segunda guerra mundial. $\mathrm{O}$ incentivo continuou por meio de subsídios à exportação, o que contribuiu de forma decisiva para a consolidação da indústria de produtos cítricos no país. Na década de 60 iniciou-se a industrialização de cítricos no Brasil, e, já em 1966, o país obteve a liderança na exportação mundial de suco concentrado congelado de laranja. A tabela 1 apresenta alguma terminologia utilizada na indústria cítrica, e as tabelas 2 e 3 apresentam, respectivamente, como estão a produção de laranja e as exportações de suco concentrado de laranja no mundo nos últimos anos (note a destacada liderança do Brasil na produção e exportação deste produto).

\subsection{O processo de produção, mistura e distribuição de suco de laranja}

A seguir, descreve-se resumidamente um típico processo de produção do suco de laranja e seus subprodutos, conforme ilustrado na figura 1 . A laranja é transportada até a fábrica por meio de caminhões que, ao chegarem na empresa, são descarregados através de rampas com acionamento hidráulico ("descarregamento de frutas" figura 1). A fruta é transportada através de correias e elevadores de canecas até os silos de estocagem de laranja ("silos de armazenagem de frutas" - figura 1). Durante o descarregamento da fruta, é coletada uma amostra representativa da carga do caminhão, para que seja feita a identificação das características físico-químicas desta. As principais características são o brix, ratio, variedade, as quais foram descritas na tabela 1.

Com base nas características físico-químicas da laranja e no plano de produção, é feita a retirada da fruta dos silos por meio de correias transportadoras e elevadores de canecas, a qual é encaminhada ao setor de lavagem e seleção ("lavação e escolha" - figura 1). Neste setor, a laranja é lavada primeiro com água e, em seguida, com água clorada, para a devida assepsia. Após a lavagem, a laranja passa por um processo de seleção, onde são retiradas manualmente as frutas deterioradas e verdes (estas frutas são transportadas por bombeamento para o setor de produção do pellet de polpa cítrica, que é um subproduto da laranja utilizado como componente para ração animal). Uma vez lavada e selecionada, a fruta é transportada mais uma vez por correias transportadoras até o equipamento denominado classificador ("classificador" figura 1). Este equipamento classifica a laranja em três diferentes grupos conforme o tamanho da fruta (pequena, média e grande). Depois de classificada, a laranja é processada no setor conhecido por extração ("sala asséptica de extração" - figura 1). É neste local que temos o equipamento conhecido por extratora, o qual fornece as seguintes fases a partir da laranja: suco com polpa, emulsão água com óleo e fragmentos de casca da laranja, e bagaço da laranja.

A fase "bagaço da laranja" é conduzida por meio de roscas transportadoras até o setor chamado de ração. Neste setor o bagaço é armazenado em um silo ("caixa de bagaço" figura 1) a partir do qual adiciona-se cal para corrigir o pH e tornar o bagaço da laranja menos viscoso (KESTERSON \& BRADDOCK, 1976). Feito isso o bagaço passa por uma seqüência de equipamentos, até resultar nos subprodutos: D'limonene, que é utilizado na fabricação de solventes, resinas, entre outros, e o pellet de 
Tabela 1 - Terminologia utilizada na indústria cítrica

\begin{tabular}{|l|l|}
\hline Caixa de fruta & unidade de peso equivalente a 40,8 quilos ou 90 libras. \\
\hline Brix & $\begin{array}{l}\text { refere-se a porcentagem de sólidos solúveis ou açúcares e ácidos, sendo quantificado } \\
\text { em graus brix através de refratômetro. O refratômetro é um instrumento utilizado para } \\
\text { medir o índice de refração de soluções. }\end{array}$ \\
\hline Acidez & $\begin{array}{l}\text { depois dos açúcares, os ácidos são os sólidos solúveis presentes em maior quantidade } \\
\text { no suco. O teor de ácidos é determinado por titulação. }\end{array}$ \\
\hline Ratio & é a relação brix/acidez e fornece o grau de maturação e qualidade do suco. \\
\hline Variedade & $\begin{array}{l}\text { as variedades de laranja Pêra, Natal e Valência são as mais indicadas para a } \\
\text { industrialização, enquanto a variedade Hamlin, por ser mais precoce, permite que a } \\
\text { fábrica opere economicamente no início da safra, mas fornece um suco de qualidade } \\
\text { inferior e de pouca aceitação no mercado. }\end{array}$ \\
\hline
\end{tabular}

Tabela 2 - Produção de laranjas

\begin{tabular}{|l|r|r|r|r|r|r|r|r|}
\hline \multirow{2}{*}{$\begin{array}{l}\text { Produção laranjas } \\
\text { (em mil toneladas) }\end{array}$} & \multicolumn{9}{|c|}{ Ano } \\
\cline { 2 - 9 } & $\mathbf{1 9 9 2}$ & $\mathbf{1 9 9 3}$ & $\mathbf{1 9 9 4}$ & $\mathbf{1 9 9 5}$ & $\mathbf{1 9 9 6}$ & $\mathbf{1 9 9 7}$ & $\mathbf{1 9 9 8}$ & $\mathbf{1 9 9 9}$ \\
\hline Mundo & 54.430 & 55.239 & 54.642 & 58.744 & 61.544 & 65.432 & 63.098 & 58.168 \\
\hline Brasil & 19.657 & 18.771 & 17.418 & 19.613 & 21.865 & 22.961 & 20.723 & 19.399 \\
\hline EUA & 8.082 & 9.972 & 9.370 & 10.371 & 10.366 & 11.514 & 12.401 & 8.968 \\
\hline México & 2.541 & 2.914 & 3.191 & 3.572 & 3.985 & 3.944 & 3.329 & 3.538 \\
\hline Espanha & 2.941 & 2.523 & 2.712 & 2.587 & 2.201 & 2.819 & 2.448 & 2.500 \\
\hline China & 1.407 & 1.752 & 1.792 & 2.124 & 2.182 & 2.640 & 2.258 & 2.360 \\
\hline Índia & 1.330 & 1.895 & 2.005 & 2.080 & 2.000 & 2.000 & 2.000 & 2.000 \\
\hline Itália & 2.112 & 2.109 & 1.809 & 1.597 & 1.771 & 1.996 & 1.921 & 1.921 \\
\hline Irã & 1.819 & 1.440 & 1.584 & 1.556 & 1.670 & 1.706 & 1.749 & 1.749 \\
\hline Egito & 1.771 & 1.324 & 1.513 & 1.555 & 1.613 & 1.522 & 1.442 & 1.525 \\
\hline Paquistão & 1.166 & 1.295 & 1.353 & 1.372 & 1.400 & 1.410 & 1.410 & 1.410 \\
\hline Outros & 11.603 & 11.245 & 11.895 & 12.317 & 12.491 & 12.921 & 13.418 & 12.798 \\
\hline
\end{tabular}

Fonte: F.A.O. (2000)

Tabela 3 - Exportações de Suco Concentrado de Laranja

\begin{tabular}{|l|r|r|r|r|r|r|r|r|}
\hline \multirow{2}{*}{$\begin{array}{c}\text { Exportações de FCOJ * } \\
\text { (em mil toneladas) }\end{array}$} & \multicolumn{9}{|c|}{ Ano } \\
\cline { 2 - 10 } & $\mathbf{1 9 9 1}$ & $\mathbf{1 9 9 2}$ & $\mathbf{1 9 9 3}$ & $\mathbf{1 9 9 4}$ & $\mathbf{1 9 9 5}$ & $\mathbf{1 9 9 6}$ & $\mathbf{1 9 9 7}$ & $\mathbf{1 9 9 8}$ \\
\hline Mundo & 1.171 & 1.236 & 1.455 & 1.440 & 1.226 & 1.414 & 1.427 & 1.483 \\
\hline Brasil & 914 & 972 & 1.165 & 1.147 & 961 & 1.182 & 1.180 & 1.228 \\
\hline EUA & 147 & 159 & 123 & 88 & 91 & 103 & 122 & 92 \\
\hline Espanha & 0 & 4 & 10 & 10 & 21 & 29 & 32 & 44 \\
\hline Outros & 110 & 101 & 156 & 195 & 152 & 100 & 94 & 119 \\
\hline
\end{tabular}

${ }^{*}$ FCOJ - Suco Concentrado Congelado de Laranja (Frozen Concentrated Orange Juice)

Fonte: F.A.O. (2000) 


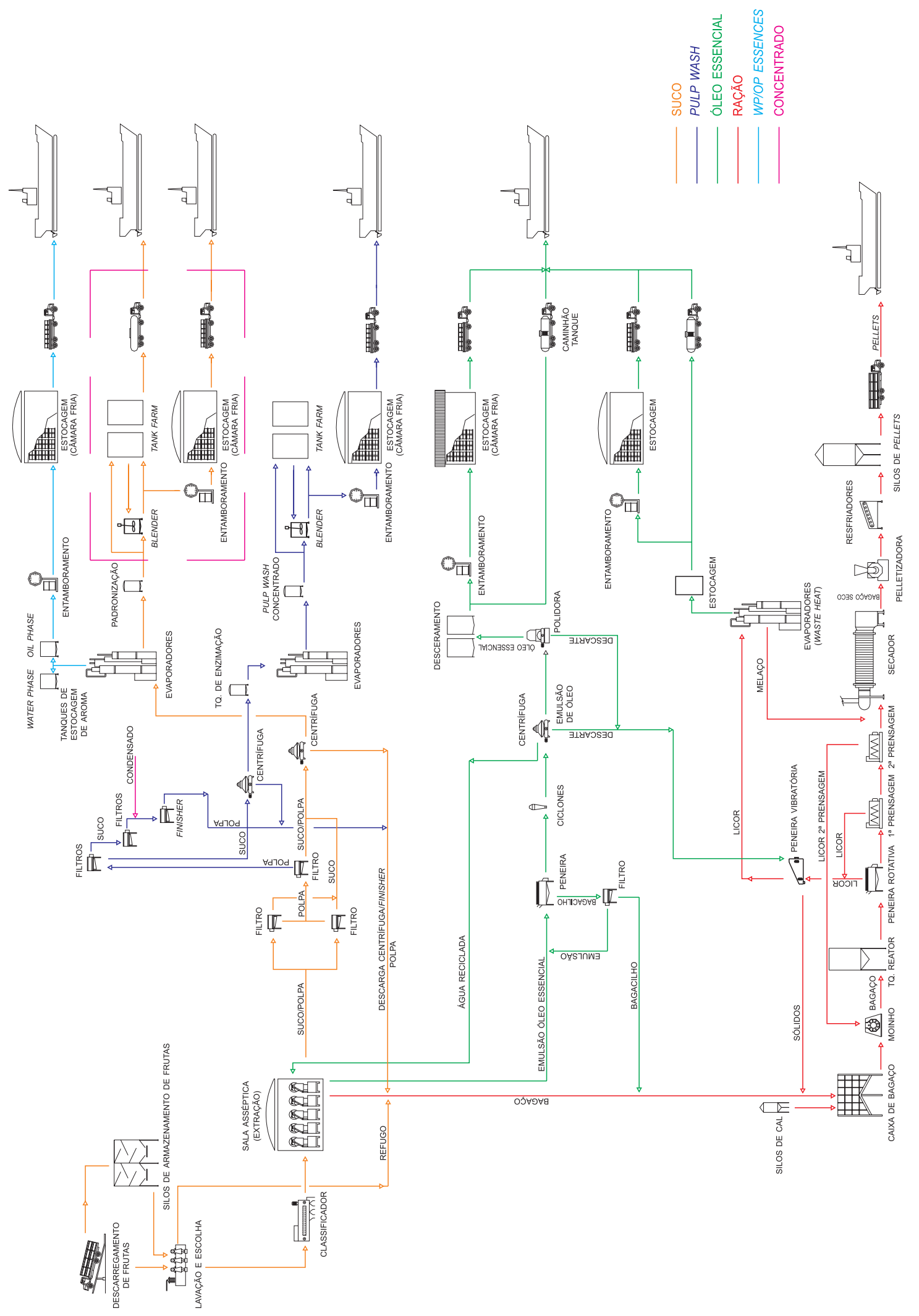

Figura 1 - Processo de suco de laranja e subprodutos 
polpa cítrica, que é utilizado como um componente na fabricação de ração animal. A fase "emulsão água com óleo e fragmentos de casca de laranja" é encaminhada, por roscas transportadoras, ao setor de produção de óleo essencial de laranja. A fase "suco com polpa" é transportada por gravidade ao setor de filtragem e centrifugação ("filtros" e "centrífugas", respectivamente - figura 1). Neste setor, é retirado do suco o excesso de polpa e outros defeitos que possam estar nele incorporados, além de se efetuar o ajuste do teor de polpa do produto dentro dos padrões desejados. A polpa retirada do suco nesta etapa é utilizada na produção do subproduto conhecido como pulp wash (polpa lavada), que vem a ser um suco com qualidade inferior.

Retornando ao suco que está com o teor de polpa desejado, o processo de industrialização segue, através da concentração do suco, até a especificação desejada em evaporadores múltiplos efeitos com filme descendente ("evaporadores" - figura 1). Após concentrado, resfria-se o suco e armazena-se este a granel em tank farms ("Tank Farm" - figura 1). Neste estágio, temos o suco na forma de bases, que serão combinadas conforme um plano de mistura e distribuição, o que é objeto deste estudo. Quando o suco está sendo concentrado nos evaporadores, ocorre a extração de outros dois subprodutos conhecidos por oil phase e water phase que, na seqüência, são armazenados em tambores metálicos de 200 litros prontos para serem comercializados.

O processo de mistura e distribuição do suco concentrado congelado de laranja se dá através de um planejamento anual (figura 2 - "Planejamento Básico da Safra"), no qual se analisam simultaneamente os estoques de passagem de uma safra para a outra, um pré-plano de vendas, um plano de frutas, um planejamento de moagem e um plano de produção. Com base nestas informações, elaboram-se os planos de mistura, movimentação, embarque e estocagem de produtos. Este processo envolve diversas áreas da empresa, tais como compras (de frutas), vendas (de sucos), produção, logística e qualidade, as quais buscam a otimização da utilização dos recursos da empresa. Um plano de mistura consiste em determinar quanto e quando misturar as diferentes bases de suco que estão estocadas nos tank farms da fábrica. Estas bases foram obtidas a partir dos planos de frutas, moagem e produção, de forma a atender ao préplano de vendas, planos de embarque e limitações de recursos, como capacidades de estocagem e mistura.

\subsection{Delimitação do problema}

Conforme discutido na seção 1 , o objeto deste estudo é o processo de mistura das diversas bases de suco nos tank farms da fábrica para produzir e armazenar os produtos finais nos tank farms (suco a granel) e nas câmaras frias (suco em tambores) da fábrica, assim como o sistema de distribuição (transporte e estocagem) destes produtos, desde os estoques da fábrica, passando pelos estoques externos (tank farms no caso de suco a granel, e câmaras frias no caso de suco em tambores), até o terminal marítimo, visando à exportação. $\mathrm{O}$ que diferencia uma base de suco de outra, assim como um produto final de outro, são principalmente as especificações de ratio e variedade. A figura 3 esquematiza esta situação numa rede de fluxos: da esquerda para a direita, o primeiro nó da figura representa o estoque de bases a granel nos tank farms da fábrica, os dois nós seguintes representam os estoques de produtos nos tank farms da fábrica (suco a granel) e nas câmaras frias da fábrica (suco em tambores), respectivamente, e os dois últimos nós representam os estoques de produtos nos tank farms externos (suco a granel) e nas câmaras frias externas (suco em tambores), respectivamente, disponíveis para serem embarcados no navio. Os arcos entre os nós representam os fluxos (mistura e transporte) de bases e produtos a granel ou em tambores entre os estoques, tudo isso para cada período (p.e., uma semana) do horizonte de planejamento (p.e., parte ou toda duração da safra). 


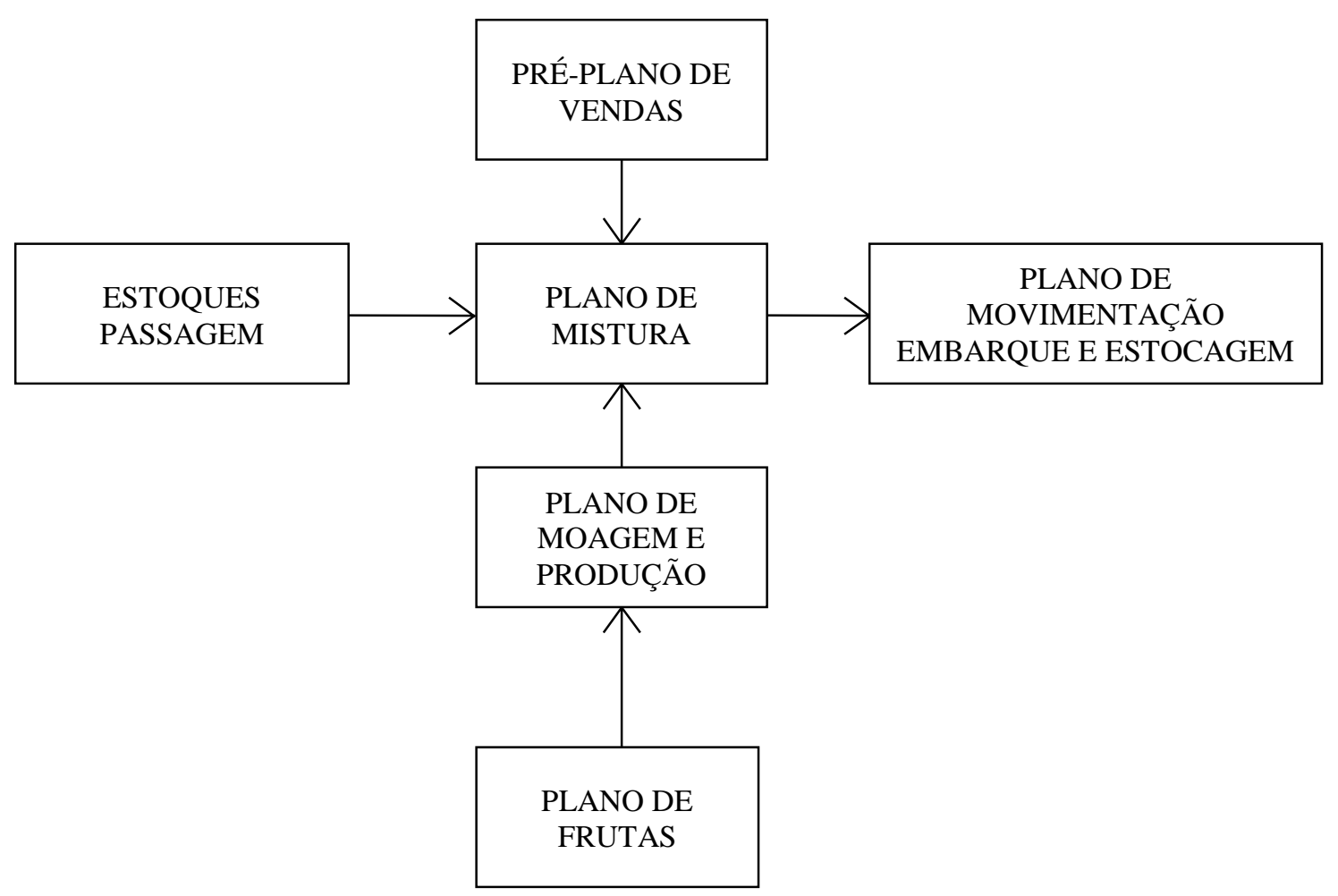

Figura 2 - Planejamento Básico da Safra

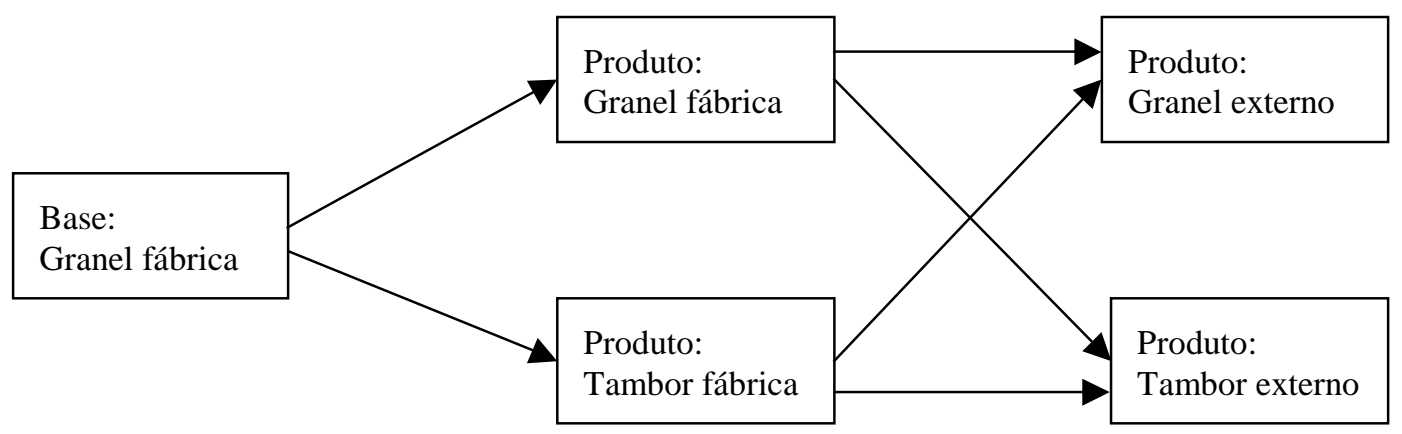

Figura 3 - Mistura de bases para produção de sucos a granel e em tambores, estoque de bases e sucos na fábrica e fora da fábrica, transporte de sucos dos estoques da fábrica para os estoques externos

Admite-se como conhecidos os planos de moagem, produção, vendas e embarque. Uma questão é determinar as quantidades e períodos em que as bases de suco devem ser utilizadas ao longo do horizonte de planejamento para a elaboração dos vários produtos. Outra questão é estabelecer as formas (a granel ou em tambores) e locais (estoques da fábrica ou estoques externos) de armazenamento destes produtos, tudo isso de maneira a miminizar o custo total. Este custo é composto dos custos de mistura, transporte e estocagem de produtos em cada período, além dos custos de antecipação de mistura e transporte de produtos em relação aos seus períodos de demanda.

Na próxima seção modela-se o problema por meio de programação linear e programação de metas, e resolve-se o modelo por meio da 
linguagem de modelagem GAMS. Por simplicidade, considera-se uma única fábrica, um único local para os tank farms externos, e um único local para as câmaras frias externas (na empresa estudada estes estoques externos estão localizados muito próximos do porto de Santos-SP), embora o modelo possa ser facilmente estendido para tratar diversas fábricas e diversos estoques externos com localizações e custos operacionais diferentes.

\section{Modelagem do Problema}

A modelagem matemática utiliza conceitos conhecidos da literatura de problemas de mistura e planejamento da produção com múltiplos produtos, estágios e períodos, conforme, por exemplo, em ACKHOFF (1962), JOHNSON \& MONTGOMERY (1974), WILLIAMS (1978), SCHRAGE (1986), NAHMIAS (1993) e SHAPIRO (1993). Entende-se aqui por distribuição, o transporte e estocagem de produtos entre diferentes locais (estoques na fábrica e externos) e formas de acondicionamento (a granel em tank farms, ou em tambores em câmaras frias). Especificações de qualidade da mistura, capacidade dos processos de mistura e estocagem, e balanceamento de material, formam as principais restrições do sistema, estas últimas responsáveis pela ligação entre os diferentes períodos de planejamento e locais de mistura e estocagem. Equações de balanceamento de material são comuns nos modelos com múltiplos estágios. Por exemplo, em WIIG (1975) é apresentado um modelo de planejamento para distribuição de derivados de petróleo, onde equações de balanceamento de material são muito utilizadas em cada ponto do sistema de distribuição.

Pode-se notar que a distribuição de suco de laranja, como descrita na seção 2 , tem características de problemas de planejamento da produção com múltiplos produtos, estágios e períodos. Pode-se também notar que o processo de mistura de suco de laranja, como descrito na seção 2 , está intimamente relacionado com problemas de mistura, onde se tem bases de suco com diferentes propriedades e custos, sendo misturadas para se obter um produto final de custo mínimo. As disponibilidades de bases de suco e as especificações do produto final formam restrições para a obtenção da mistura ótima. Problemas de mistura representam uma importante classe de modelos de programação linear (AL-SHAMMARI \& DAWOOD, 1997). Tipicamente, tais modelos giram em torno de tomar uma decisão relacionada ao melhor uso dos recursos de uma organização quando da mistura de vários ingredientes para produzir um produto final sem violar determinados critérios.

\subsection{A formulação matemática}

As tabelas 4 e 5 definem as variáveis e parâmetros utilizados na formulação matemática a seguir (todas as variáveis e parâmetros devem ser não negativos). Os índices $j, p, k, l$ e $t$ estão associados conforme segue: $j$ representa o tipo de base ("Hamlin", "BR10", ..), $p$ representa o tipo de produto ("PA11", "PA12", ...), $k$ representa o tipo de estoque da fábrica ("granel", "tambor"), $l$ representa o tipo de estoque externo ("granel", "tambor"), e $t$ representa o período $(1,2, \ldots$ semanas). Sem perda de generalidade, alguns parâmetros são supostos constantes ao longo do horizonte de planejamento.

A função objetivo $F$ a ser minimizada é a somatória dos custos de:

- misturar: $\sum_{t} \sum_{k} \sum_{j} \sum_{p} C B_{j}^{k} X B_{j p t}^{k}$

- transportar: $\sum_{t} \sum_{k} \sum_{l} \sum_{p} C T_{p}^{k l} X T_{p t}^{k l}$

- estocar: $\sum_{t} \sum_{j} H B_{j} E B_{j t}+$ $+\sum_{t} \sum_{k} \sum_{p} H P F_{p}^{k} E P F_{p t}^{k}+$ $+\sum_{t} \sum_{l} \sum_{p} H P E_{p}^{l} E P E_{p t}^{l}$

- financeiro: $\sum_{t} \sum_{k} \sum_{p} T X F^{k}\left(E P F_{p t}^{k}+E P E_{p t}^{k}\right)+$ $+\sum_{t} \sum_{l} \sum_{p} T X E_{p}^{l} E P E_{p t}^{l}$ 
Tabela 4 - Variáveis

\begin{tabular}{|l|l|}
\hline Notação & Descrição \\
\hline$X B_{j p t}^{k}$ & $\begin{array}{l}\text { Quantidade (em toneladas) da base } j \text { utilizada para produzir o produto } p \text { no período } t \text {. Esta quantidade sai do } \\
\text { tank farm da fábrica como base } j \text { e entra no estoque } k \text { (granel ou tambor) da fábrica como produto } p\end{array}$ \\
\hline$X T_{p t}^{k l}$ & $\begin{array}{l}\text { Quantidade (em toneladas) do produto } p \text { transportada do estoque } k \text { (granel ou tambor) da fábrica para o estoque } \\
\text { externo } l \text { (granel ou tambor) no período } t\end{array}$ \\
\hline$E B_{j t}$ & Quantidade (em toneladas) da base $j$ no tank farm da fábrica no final do período $t$ \\
\hline$E P F_{p t}^{k}$ & Quantidade (em toneladas) do produto $p$ no estoque $k$ (granel ou tambor) da fábrica no final do período $t$ \\
\hline$E P E_{p t}^{l}$ & Quantidade (em toneladas) do produto $p$ no estoque externo $l$ (granel ou tambor) no final do período $t$ \\
\hline$F$ & Custo total de mistura, transporte, armazenagem e financeiro, para o horizonte de planejamento \\
\hline
\end{tabular}

Tabela 5 - Parâmetros

\begin{tabular}{|c|c|}
\hline Notação & Descrição \\
\hline$B_{t}$ & Capacidade de mistura na fábrica (em toneladas/período) no período $t$ \\
\hline$A B^{k}$ & Capacidade (em toneladas) do estoque $k$ da fábrica (suposta constante ao longo dos períodos) \\
\hline$A T^{l}$ & Capacidade (em toneladas) do estoque externo $l$ (suposta constante ao longo dos períodos) \\
\hline$R A T B_{j}$ & Ratio médio da base $j$ \\
\hline$R A T P_{p}$ & Ratio mínimo do produto $p$ \\
\hline$C B_{j}^{k}$ & $\begin{array}{l}\text { Custo unitário (em unidades monetárias/tonelada) de mistura da base } j \text { do tank farm da fábrica para o estoque } k \\
\text { da fábrica (suposto constante ao longo dos períodos) }\end{array}$ \\
\hline$C T_{p}^{k l}$ & $\begin{array}{l}\text { Custo unitário (em unidades monetárias/tonelada) de transporte do produto } p \text { do estoque } k \text { da fábrica para o } \\
\text { estoque externo } l \text { (suposto constante ao longo dos períodos). No caso de transporte de estoque a granel para } \\
\text { estoque em tambor, ou estoque em tambor para estoque a granel, o custo unitário de transporte inclui um custo } \\
\text { unitário de alteração da forma de acondicionamento do produto. }\end{array}$ \\
\hline$H B_{j}$ & $\begin{array}{l}\text { Custo unitário (em unidades monetárias/tonelada/período) de estocagem da base } j \text { no tank farm da fábrica } \\
\text { (suposto constante ao longo dos períodos) }\end{array}$ \\
\hline$H P F_{p}^{k}$ & $\begin{array}{l}\text { Custo unitário (em unidades monetárias/tonelada/período) de estocagem do produto } p \text { no estoque } k \text { da fábrica } \\
\text { (suposto constante ao longo dos períodos) }\end{array}$ \\
\hline$H P E_{p}^{l}$ & $\begin{array}{l}\text { Custo unitário (em unidades monetárias/tonelada/período) de estocagem do produto } p \text { no estoque externo } l \\
\text { (suposto constante ao longo dos períodos) }\end{array}$ \\
\hline$P R_{j t}$ & Produção (em toneladas) de base $j$ no período $t$ \\
\hline$D_{p t}^{l}$ & Demanda (em toneladas) de produto $\mathrm{p}$ no estoque externo $l$ no período $t$ \\
\hline$P E R C_{t}$ & Porcentagem de base tipo hamlin adicionada ao produto acabado no período $t$ \\
\hline$T X F^{k}$ & $\begin{array}{l}\text { Custo financeiro unitário médio (em unidades monetárias/tonelada) de antecipar a mistura por um período no } \\
\text { estoque } k \text { da fábrica }\end{array}$ \\
\hline$T X E_{p}^{l}$ & $\begin{array}{l}\text { Custo financeiro unitário médio (em unidades monetárias/tonelada) de antecipar o transporte do produto } p \text { por } \\
\text { um período no estoque externo } l\end{array}$ \\
\hline
\end{tabular}


Note na expressão acima que
$T X F^{k}\left(E P F_{p t}^{k}+E P E_{p t}^{k}\right)$ é o custo financeiro associado ao nível de estoque do produto $p$ no estoque $k$ da fábrica e externo no período $t$ que excede a sua demanda neste período. Este custo é calculado apenas sobre as despesas de antecipar a mistura por um período para a obtenção deste produto. Similarmente, $T X E_{p}^{l} E P E_{p t}^{l}$ é o custo financeiro associado ao nível de estoque do produto $p$ no estoque externo $l$ no período $t$. Este custo é calculado apenas sobre as despesas de antecipar o transporte do produto $p$ por um período relativamente à sua demanda.

Portanto, a função objetivo do modelo é:

$$
\begin{aligned}
\operatorname{Min} F & =\sum_{t} \sum_{k} \sum_{j} \sum_{p} C B_{j}^{k} X B_{j p t}^{k}+ \\
& +\sum_{t} \sum_{k} \sum_{l} \sum_{p} C T_{p}^{k l} X T_{p t}^{k l}+ \\
& +\sum_{t} \sum_{j} H B_{j} E B_{j t}+ \\
& +\sum_{t} \sum_{k} \sum_{p} H P F_{p}^{k} E P F_{p t}^{k}+ \\
& +\sum_{t} \sum_{l} \sum_{p} H P E_{p}^{l} E P E_{p t}^{l}+ \\
& +\sum_{t} \sum_{k} \sum_{p} T X F^{k}\left(E P F_{p t}^{k}+E P E_{p t}^{k}\right)+ \\
& +\sum_{t} \sum_{l} \sum_{p} T X E_{p}^{l} E P E_{p t}^{l}
\end{aligned}
$$

As restrições do modelo referem-se a atualização de estoques, limitantes para ratios da mistura, adição de base tipo hamlin na mistura, e capacidade de estocagem e de mistura.

- Restrições de atualização de estoques por período, produto/base e local:

$$
\begin{gathered}
E B_{j t}=E B_{j(t-1)}+P R_{j t}-\sum_{k} \sum_{p} X B_{j p t}^{k} \\
\forall j, t \\
E P F_{p t}^{k}=E P F_{p(t-1)}^{k}+\sum_{j} X B_{j p t}^{k}-\sum_{l} X T_{p t}^{k l} \\
\forall k, p, t
\end{gathered}
$$

$$
\begin{gathered}
E P E_{p t}^{l}=E P E_{p(t-1)}^{l}+\sum_{k} X T_{p t}^{k l}-D_{p t}^{l} \\
\forall l, p, t
\end{gathered}
$$

As equações de balanceamento de material (2)-(4) são típicas de problemas de planejamento da produção com múltiplos produtos, estágios e períodos. Note que $E B_{j t}$ em (2) é o estoque de cada base $j$ no tank farm da fábrica no final do período $t$. Este estoque é obtido somando-se ao estoque do final do período anterior $\left(E B_{j(t-1)}\right)$ a produção no período $\left(P R_{j t}\right)$, e subtraindo-se a quantidade de base misturada no período para a obtenção de produtos finais $\left(\sum_{k} \sum_{p} X B_{j p t}^{k}\right)$. Similarmente para $E P F_{p t}^{k}$ em (3) e $E P E_{p t}^{l}$ em (4).

- Restrições de limitantes de ratios resultantes da mistura por local, período e produto:

$$
\begin{aligned}
& \sum_{j}\left(R A T B_{j} X B_{j p t}^{k}\right) \leq\left(R A T P_{p}+0,8\right) \sum_{j} X B_{j p t}^{k} \\
& \forall k, p, t \\
& \sum_{j}\left(R A T B_{j} X B_{j p t}^{k}\right) \geq R A T P_{p} \sum_{j} X B_{j p t}^{k} \\
& \forall k, p, t
\end{aligned}
$$

As equações (5)-(6) são típicas de problemas de mistura, onde é preciso determinar as quantidades de bases de suco que devem ser combinadas, para se obter um produto com determinadas especificações. A equação (5) estabelece o limite superior $\left(R A T P_{p}+0,8\right)$ para o ratio do produto $p$, enquanto que a equação (6) estabelece o limite inferior $\left(R A T P_{p}\right)$.

- Restrição de adição de base tipo hamlin na mistura por local, período e produto:

$$
\begin{array}{r}
X B_{\text {"hamlin"pt }}^{k}=P E R C_{t} \sum_{j} X B_{j p t}^{k} \\
\forall k, p, t
\end{array}
$$

A restrição (7) tem a mesma característica das restrições anteriores (5)-(6), isto é, são 
típicas de problemas de mistura, e estabelece a porcentagem $P E R C_{t}$ de base de suco do tipo $j=$ "hamlin" que deve ser adicionada ao produto $p$ em cada período $t$.

- Restrição de capacidade de estocagem nos tank farms da fábrica e externos, e nas câmaras frias da fábrica e externas:

$$
\begin{array}{lr}
\sum_{j} E B_{j t}+\sum_{p} E P F_{p t}^{\text {"granel" }} \leq A B^{\text {granel" }} \forall t \\
\sum_{p} E P F_{p t}^{\text {"tambor" }} \leq A B^{\text {ttambor" }} & \forall t \\
\sum_{p} E P E_{p t}^{l} \leq A T^{l} & \forall l, t
\end{array}
$$

A equação (8) estabelece que a soma dos estoques de bases e produtos a granel nos tank farms da fábrica ( $k=$ "granel") no final do período $t$ não pode exceder a capacidade $A B^{\text {"granel" }}$. A equação (9) estabelece que os estoques de produtos em tambor nas câmaras frias da fábrica ( $k=$ "tambor") no final do período $t$ não podem exceder $A B^{\text {"tambor" }}$, e a equação (10) estabelece que os estoques externos de produtos ( $l=$ "granel" ou "tambor") no final do período $t$ não podem exceder a capacidade $A T^{l}$.

- Restrição de capacidade de mistura

$$
\sum_{k} \sum_{j} \sum_{p} X B_{j p t}^{k} \leq B_{t} \quad \forall t
$$

A equação (11) estabelece a quantidade máxima de suco $B_{t}$ que pode ser misturada em cada período $t$.

O modelo de programação linear (1)-(11), junto com as restrições de não negatividade das variáveis, foi codificado na linguagem de modelagem $G A M S$ e resolvido num microcomputador pelo solver GAMS/MINOS (BROOKE et al., 1992), conforme é discutido na seção 4. Convém salientar que o modelo (1)-(11) pode ser facilmente adaptado para tratar situações em que os custos são convexos, aproximando-os por funções lineares por partes (veja, p.e., BAZARAA et al., 1990).

\subsection{Uma abordagem de programação de metas}

A programação de metas é uma simples modificação e extensão de programação linear, que permite uma solução simultânea de um sistema de objetivos complexos, ao invés de um único e simples objetivo (HAX \& CANDEA, 1984). Ela pode ser aplicada quando vários objetivos aparecem explicitamente e os tradeoffs entre os objetivos devem ser analisados com base em um conjunto de prioridades. Em particular, quando não é possível determinar precisamente a importância relativa dos objetivos, a chamada programação de metas preemptive pode ser uma ferramenta útil (WINSTON, 1991). Para maiores detalhes de programação de metas, o leitor pode consultar, por exemplo, HAX \& CANDEA (1984), OZAN (1986), HILLIER \& LIEBERMAN (1988) e WINSTON (1991).

No sistema de mistura de suco de laranja descrito na seção 2.2, pode ocorrer a necessidade de decisões gerenciais envolvendo vários objetivos. Muitas vezes, quando na elaboração do plano de mistura, deseja-se, além de minimizar custos, que os produtos fiquem o mais próximo possível da média de suas especificações mínimas e máximas de ratio. Por exemplo, em um produto com especificações 14 e 15 , é desejável que seu ratio fique o mais próximo possível da média 14,5. Para tratar esta situação, a especificação de um conjunto de metas, com níveis de prioridades associados a cada uma delas, pode ser a seguinte:

- A meta 1 , de maior prioridade, é minimizar a somatória dos custos de misturar, transportar, armazenar e financeiro (equação (1)), ou, equivalentemente, minimizar o desvio destes custos do objetivo "custo zero";

- A meta 2, de prioridade secundária, é minimizar o desvio da especificação de ratio médio para os diversos produtos. 
Tabela 6 - Variáveis de desvio

\begin{tabular}{|l|l|}
\hline Notação & Descrição \\
\hline$S_{1}^{+}$ & $\begin{array}{l}\text { Variável de desvio indicando o quanto a somatória dos custos de misturar, transportar, armazenar } \\
\text { e financeiro está acima da meta 1: "custo zero" }\end{array}$ \\
\hline $\begin{array}{c}\boldsymbol{S}_{2 p t} \\
\boldsymbol{S}_{2 p t}^{k-}\end{array}$ & $\begin{array}{l}\text { Variável de desvio indicando o quanto o produto p no período t no estoque k da fábrica, está } \\
\text { acima da especificação de ratio intermediária desejada pela meta } 2 \text { (em quantidade x ratio) }\end{array}$ \\
\hline
\end{tabular}

Definindo as variáveis de desvio conforme a tabela 6 , obtemos uma nova função objetivo, para substituir a função objetivo (1) do modelo (1)-(11), dada por:

$$
\min P_{1}\left(s_{1}^{+}\right)+P_{2}\left(\sum_{t} \sum_{k} \sum_{p} c_{p}\left(s_{2 p t}^{k+}+s_{2 p t}^{k-}\right)\right)
$$

onde $P_{1} \gg P_{2}$ e $c_{p}$ é um peso relativo para cada produto $p$ (neste trabalho utilizou-se $c_{p}=1$ ). As restrições (2)-(11) continuam válidas. É necessário ainda adicionar ao modelo as seguintes restrições de metas 1 e 2 :

- Restrição da meta 1 , obtida a partir da equação (1):

$$
\begin{aligned}
& \sum_{t} \sum_{k} \sum_{j} \sum_{p} C B_{j}^{k} X B_{j p t}^{k}+ \\
+ & \sum_{t} \sum_{k} \sum_{l} \sum_{p} C T_{p}^{k l} X T_{p t}^{k l}+\sum_{t} \sum_{j} H B_{j} E B_{j t}+ \\
+ & \sum_{t} \sum_{k} \sum_{p} H P F_{p}^{k} E P F_{p t}^{k}+ \\
+ & \sum_{t} \sum_{l} \sum_{p} H P E_{p}^{l} E P E_{p t}^{l}+ \\
+ & \sum_{t} \sum_{k} \sum_{p} T X F^{k}\left(E P F_{p t}^{k}+E P E_{p t}^{k}\right)+ \\
+ & \sum_{t} \sum_{l} \sum_{p} T X E_{p}^{l} E P E_{p t}^{l}-s_{1}^{+}=0
\end{aligned}
$$

- Restrição da meta 2, obtida a partir das equações (5) e (6):

$$
\begin{gathered}
\sum_{j}\left(R A T B_{j} X B_{j p t}^{k}\right)-s_{2 p t}^{k+}+S_{2 p t}^{k-}= \\
=\left(R A T P_{p}+0,4\right) \sum_{j} X B_{j p t}^{k} \quad \forall k, p, t
\end{gathered}
$$

Note que a restrição (13), junto a nova função objetivo (12), estabelece que o custo total de misturar, transportar, armazenar e financeiro, deve ser o mais próximo possível de zero. Similarmente, a restrição (14) estabelece que o ratio médio do produto $p$ no estoque $k$ da fábrica, obtido a partir das misturas das várias bases $j$ em cada período $t$, deve ser o mais próximo possível do valor médio da faixa de ratio permitida para este produto $\left(R A T P_{p}+0,4\right)$.

O modelo linear de programação de metas preemptive (2)-(14), junto com as restrições de não negatividade das variáveis, também foi codificado na linguagem de modelagem GAMS e resolvido num microcomputador pelo solver GAMS/MINOS, conforme é discutido na seção 4. Para isso, inicialmente resolveu-se o problema (2)-(14) minimizando o desvio da meta 1 (custo zero), ou seja, simplesmente ignorando-se a meta 2 da função objetivo (12), para obter-se o custo mínimo $F^{*}$. Em seguida, resolveu-se o problema (2)-(14) minimizando o desvio da meta 2 (ratio médio) sob a meta 1 , ou seja, ignorando-se a meta 1 da função objetivo (12) e adicionando-se no modelo a restrição de custo mínimo: $S_{1}^{+}=F^{*}$.

\section{Resultados Computacionais e Análise}

Conforme mencionado na seção 3 , os modelos lineares (1)-(11) e (2)-(14) foram codificados em GAMS, uma linguagem de modelagem projetada para a elaboração e solução de problemas de programação matemática grandes 
e complexos (BROOKE et al., 1992). O sistema simplifica a preparação de dados e relatórios e a transformação dos dados na forma requerida pelos otimizadores (solvers) nele contidos, ambas geralmente responsáveis por grande parte do tempo gasto no desenvolvimento de um modelo (FERNANDES \& MORABITO, 1993). GAMS possui o solver GAMS/MINOS, um sistema baseado na linguagem FORTRAN e projetado para resolver problemas de otimização lineares e não-lineares. GAMS/MINOS resolve modelos lineares utilizando uma implementação do método primal simplex. O leitor pode obter mais informações sobre o método simplex, por exemplo, em BAZARAA et al. (1990). Maiores detalhes da implementação e solução dos modelos (1)-(11) e (2)-(14) na linguagem GAMS podem ser encontrados em MUNHOZ (2000).

\subsection{Aplicação do modelo de minimização de custos}

A análise do modelo (1)-(11) foi realizada em uma simplificação do problema real, devido à indisponibilidade de dados e para proteger interesses da empresa. Os parâmetros utilizados foram distorcidos, porém, procurou-se manter relativa proporcionalidade, para fins de validação do modelo. Por simplicidade de análise, reduzimos o número de períodos, quantidades de bases e produtos finais, em relação à situação real, conforme a tabela 7 . A tabela 8 compara o número de variáveis e restrições do modelo (1)-(11) para os problemas real e simplificado. Convém salientar que, apesar de estarmos resolvendo um problema de tamanho muito menor do que o problema real (apenas 195 restrições, ao invés de 4233), isto não é uma limitação para a metodologia empregada (linguagem de modelagem GAMS com solver GAMS/MINOS).

Com base na experiência adquirida por um dos autores nestes últimos doze anos de atuação no setor de suco de laranja (desde 1988), são explorados diversos cenários para avaliar o comportamento do modelo ao se perturbar determinados parâmetros. Inicialmente foram considerados quatro cenários que exploram alterações nas capacidades de mistura, estocagem a granel nos tank farms da fábrica, e estocagem a granel nos tank farms externos. A tabela 9 apresenta parte dos parâmetros utilizados em cada um destes cenários; os demais parâmetros $R A T B_{j}, R_{A T P_{p}}, C B_{j}^{k}, C T_{p}^{k l}, H B_{j}, H P F_{p}^{k}$, $H P E_{p}^{l}, T X F^{k}, T X E_{p}^{l}$ foram considerados fixos para os quatro cenários e podem ser encontrados em MUNHOZ (2000). As tabelas 10-12 apresentam um resumo dos resultados obtidos com o modelo (1)-(11) em cada um dos cenários (as soluções foram encontradas pelo solver GAMS/MINOS na ordem de segundos, utilizando-se um microcomputador Pentium). A seguir analisa-se os resultados de cada cenário.

\section{Cenário 1}

A solução de custo mínimo do modelo (1)-(11) resulta em $F^{*}=3018.1$ unidades monetárias (u.m.), conforme a tabela 10. A demanda ocorre no período 5 (tabela 9), enquanto os produtos são produzidos nos períodos 3, 4 e 5 (tabela 10). São respeitadas as capacidades de estocagem e mistura. Também, pode-se constatar que, como a capacidade de mistura neste cenário é de 292 toneladas por período (tabela 9), e a demanda por produtos está concentrada no quinto período em 870 toneladas (tabela 9), então o modelo determina que sejam efetuadas misturas em mais de um período (tabela 10), de forma a respeitar a restrição de capacidade de mistura.

O ratio resultante da mistura está conforme os limites estabelecidos. A adição de base do tipo "Hamlin" também está dentro do especificado. O modelo evita misturar e/ou transportar bases e/ou produtos antes da demanda ocorrer. Por exemplo, o transporte de produtos é realizado apenas no quinto período, que é quando ocorre a demanda. Neste cenário, cabe ressaltar que o modelo determina que haja mistura de bases nos períodos 3 e 4 (tabela 10), devido à limitação de capacidade de mistura. 
Tabela 7 - Parâmetros dos problema real e simplificado

\begin{tabular}{|l|c|c|}
\hline & Problema real & Problema simplificado \\
\hline Número de períodos & 51 & 5 \\
\hline Quantidade de bases de suco & 8 & 4 \\
\hline Quantidade de produtos finais & 7 & 3 \\
\hline Estoques na fábrica & 2 & 2 \\
\hline Estoques externos & 2 & 2 \\
\hline
\end{tabular}

Tabela 8 - Número de variáveis e restrições dos problemas real e simplificado

\begin{tabular}{|l|c|c|}
\hline & Problema real & Problema simplificado \\
\hline Variáveis de mistura & 5712 & 120 \\
\hline Variáveis de transporte & 1428 & 60 \\
\hline Variáveis de estoque & 1836 & 80 \\
\hline Total de variáveis & 8976 & 260 \\
\hline Restrições de atualização de estoques & 1836 & 80 \\
\hline Restrições de mistura & 2142 & 90 \\
\hline Restrições de capacidade de estocagem & 204 & 20 \\
\hline Restrições de capacidade de mistura & 51 & 5 \\
\hline Total de restrições & 4233 & 195 \\
\hline
\end{tabular}

\section{Cenário 2}

Para avaliar como o modelo se comporta com uma maior capacidade de mistura, no quarto período tal capacidade foi aumentada de 292 para 870 toneladas (tabela 9), ou seja, suficiente para atender toda demanda de 870 toneladas do quinto período. A solução de custo mínimo do modelo (1)-(11) para este cenário $\left(F^{*}=3018.0\right.$ u.m., conforme tabela 10) é apenas um pouco melhor do que a do cenário 1 $\left(F^{*}=3018.1\right.$ u.m. $)$, devido a haver necessidade de antecipação de mistura de bases apenas no período 4 pela limitação de capacidade de mistura no período 5. Havendo antecipação de mistura apenas no período 4, o custo financeiro relativo a esta antecipação é menor relativamente ao primeiro cenário.

\section{Cenário 3}

Para avaliar como o modelo se comporta com uma menor capacidade de estocagem nos tank farms da fábrica, reduziu-se tal capacidade de 2790 para 800 toneladas (tabela 9). A solução de custo mínimo obtida do modelo $\left(F^{*}=3029\right.$ u.m., conforme tabela 10) foi antecipar parte da mistura do período 4 para o período 3 (tabela 10), e antecipar parte do transporte a granel nos períodos 3 e 4, dos tank farms da fábrica para os tank farms externos (tabela 11). Esta alteração gerou um aumento no custo total em relação ao cenário 2 de 11 u.m. (i.e., de 3018 para 3029 u.m.), devido ao custo adicional de estocar externamente à fábrica, e ao custo financeiro de antecipar a mistura e o transporte dos produtos. Note que, ao agregarmos as decisões de mistura 
Tabela 9 - Parâmetros utilizados nos 4 cenários: $P E R C_{t}, B_{t}, A B^{k}, A T^{l}, D_{p t}^{l}$ e $P R_{j t}$

\begin{tabular}{|c|c|c|c|c|c|c|}
\hline \multirow{2}{*}{ Parâmetro } & \multirow{2}{*}{ Unidade } & \multirow{2}{*}{ Período $t$} & \multicolumn{4}{|c|}{ Cenário } \\
\hline & & & 1 & 2 & 3 & 4 \\
\hline$P E R C_{t}, t=1, . ., 5$ & $\%$ & & 10 & 10 & 10 & 10 \\
\hline \multirow{5}{*}{ Cap. Mistura $B_{t}$} & ton & 1 & 292 & 292 & 292 & 292 \\
\hline & ton & 2 & 292 & 292 & 292 & 292 \\
\hline & ton & 3 & 292 & 292 & 292 & 292 \\
\hline & ton & 4 & 292 & 870 & 870 & 870 \\
\hline & ton & 5 & 292 & 292 & 292 & 292 \\
\hline Cap. est. $A B^{\text {"granel" }}$ & ton & & 2.790 & 2.790 & 800 & 800 \\
\hline Cap. est. $A T^{\text {"granel" }}$ & ton & & 1.650 & 1.650 & 1.650 & 200 \\
\hline Cap. est. $A B^{\text {"tambor" }}$ & ton & & - & - & - & - \\
\hline Cap. est. $A T^{\text {"tambor" }}$ & ton & & 100.000 & 100.000 & 100.000 & 100.000 \\
\hline \multirow{5}{*}{$\begin{array}{l}\text { Demanda } D_{\text {"PA12" } t}^{\text {"granel" }} \\
\text { especificação de ratio: } 12.0 \text { a } 12.9\end{array}$} & ton & 1 & & & & \\
\hline & ton & 2 & & & & \\
\hline & ton & 3 & & & & \\
\hline & ton & 4 & & & & \\
\hline & ton & 5 & 330 & 330 & 330 & 330 \\
\hline \multirow{5}{*}{$\begin{array}{l}\text { Demanda } D^{\prime \prime} \text { "granel" } \\
\text { especificação de ratio: } 13.0 \text { a } 13.9\end{array}$} & ton & 1 & & & & \\
\hline & ton & 2 & & & & \\
\hline & ton & 3 & & & & \\
\hline & ton & 4 & & & & \\
\hline & ton & 5 & 440 & 440 & 440 & 440 \\
\hline \multirow{5}{*}{$\begin{array}{l}\text { Demanda } D^{\prime \prime} \text { "tamboror" } \\
\text { especificação de ratio: } 11.0 \text { a } 11.9\end{array}$} & ton & 1 & & & & \\
\hline & ton & 2 & & & & \\
\hline & ton & 3 & & & & \\
\hline & ton & 4 & & & & \\
\hline & ton & 5 & 100 & 100 & 100 & 100 \\
\hline \multirow{5}{*}{ Produção $P R_{" B R 10^{\prime \prime} t}$} & ton & 1 & & & & \\
\hline & ton & 2 & 110 & 110 & 110 & 110 \\
\hline & ton & 3 & & & & \\
\hline & ton & 4 & & & & \\
\hline & ton & 5 & & & & \\
\hline \multirow{5}{*}{ Produção $P R_{" B R 11^{\prime \prime} t}$} & ton & 1 & & & & \\
\hline & ton & 2 & 90 & 90 & 90 & 90 \\
\hline & ton & 3 & 100 & 100 & 100 & 100 \\
\hline & ton & 4 & 90 & 90 & 90 & 90 \\
\hline & ton & 5 & & & & \\
\hline \multirow{5}{*}{ Produção $P R_{" B R 14 " t}$} & ton & 1 & 140 & 140 & 140 & 140 \\
\hline & ton & 2 & 90 & 90 & 90 & 90 \\
\hline & ton & 3 & 190 & 190 & 190 & 190 \\
\hline & ton & 4 & 200 & 200 & 200 & 200 \\
\hline & ton & 5 & & & & \\
\hline \multirow{5}{*}{ Produção $P R_{\text {"Hamlin"t }}$} & ton & 1 & 150 & 150 & 150 & 150 \\
\hline & ton & 2 & & & & \\
\hline & ton & 3 & & & & \\
\hline & ton & 4 & & & & \\
\hline & ton & 5 & & & & \\
\hline
\end{tabular}

Obs: os parâmetros em negrito na tabela acima representam os valores que foram alterados, relativamente ao cenário imediatamente anterior. 
Tabela 10 - Resultados: custo mínimo $F *$ em unidades monetárias (u.m.), quantidades misturadas de bases $X B_{j p t}^{k}$ e produção resultante da mistura (em toneladas), em cada período dos 4 cenários

\begin{tabular}{|c|c|c|c|c|c|c|}
\hline \multirow{2}{*}{ Variável } & \multirow{2}{*}{ Unidade } & \multirow{2}{*}{ Período } & \multicolumn{4}{|c|}{ Cenário } \\
\hline & & & 1 & 2 & 3 & 4 \\
\hline Custo total $F^{*}$ & u.m. & & 3018.1 & 3018.0 & 3029 & 3724 \\
\hline \multirow{5}{*}{ Qtde. misturada $X B_{j^{\prime \prime B R 10 " t}}^{k}$} & ton & 1 & - & - & - & - \\
\hline & ton & 2 & - & - & - & - \\
\hline & ton & 3 & 48 & - & - & - \\
\hline & ton & 4 & - & 49 & - & 98 \\
\hline & ton & 5 & 61 & 61 & 61 & 12 \\
\hline \multirow{5}{*}{ Qtde. misturada $X B_{j^{\prime B R 11^{\prime \prime} t}}^{k}$} & ton & 1 & - & - & - & - \\
\hline & ton & 2 & - & - & - & - \\
\hline & ton & 3 & 119 & - & 29 & 10 \\
\hline & ton & 4 & 68 & 187 & 158 & 180 \\
\hline & ton & 5 & 93 & 93 & 93 & 90 \\
\hline \multirow{5}{*}{ Qtde. misturada $X B_{j^{\prime B R} 14^{\prime \prime} t}^{k}$} & ton & 1 & - & - & - & - \\
\hline & ton & 2 & - & - & - & - \\
\hline & ton & 3 & 138 & - & 34 & 52 \\
\hline & ton & 4 & 147 & 284 & 300 & 274 \\
\hline & ton & 5 & 109 & 109 & 109 & 180 \\
\hline \multirow{5}{*}{ Qtde. misturada $X B_{j^{\prime \prime H a m l i n} t}^{k}$} & ton & 1 & - & - & - & - \\
\hline & ton & 2 & - & - & - & - \\
\hline & ton & 3 & 29 & - & 7 & 7 \\
\hline & ton & 4 & 29 & 58 & 51 & 57 \\
\hline & ton & 5 & 29 & 29 & 29 & 29 \\
\hline \multirow[t]{5}{*}{ Ratio/Qtde produzida "PA12gr" } & ton & 1 & - & - & - & - \\
\hline & ton & 2 & - & - & - & - \\
\hline & ton & 3 & - & - & - & - \\
\hline & ton & 4 & $12.9 / 138$ & $12.9 / 138$ & $12.9 / 138$ & $12.9 / 144$ \\
\hline & ton & 5 & $12.9 / 192$ & $12.9 / 192$ & $12.9 / 192$ & $12.9 / 186$ \\
\hline \multirow[t]{5}{*}{ Ratio/Qtde produzida "PA13gr" } & ton & 1 & - & - & - & - \\
\hline & ton & 2 & - & - & - & - \\
\hline & ton & 3 & $13.1 / 286$ & - & $13.1 / 70$ & $13.9 / 70$ \\
\hline & ton & 4 & $13.1 / 154$ & $13.1 / 440$ & $13.1 / 370$ & $13.1 / 264$ \\
\hline & ton & 5 & - & - & - & $13.9 / 106$ \\
\hline \multirow[t]{2}{*}{ Ratio/Qtde produzida "PA11tb" } & ton & 1 & - & - & - & - \\
\hline & ton & 2 & - & - & - & - \\
\hline \multirow[t]{3}{*}{ especificação de ratio: 11.0 a 11.9} & ton & 3 & - & - & - & \\
\hline & ton & 4 & - & - & - & $11.2 / 100$ \\
\hline & ton & 5 & $11.9 / 100$ & $11.9 / 100$ & $11.9 / 100$ & \\
\hline \multirow[t]{5}{*}{ Ratio/Qtde produzida"PA13tb" } & ton & 1 & - & - & - & \\
\hline & ton & 2 & - & - & - & 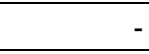 \\
\hline & ton & 3 & - & - & - & \\
\hline & ton & 4 & - & - & - & $13.1 / 60$ \\
\hline & ton & 5 & - & - & - & \\
\hline
\end{tabular}


Tabela 11 - Resultados: quantidades transportadas de produtos $X T_{p t}^{k l}$ (em toneladas), em cada período dos 4 cenários

\begin{tabular}{|c|c|c|c|c|c|c|}
\hline \multirow{2}{*}{ Variável } & \multirow{2}{*}{ Unidade } & \multirow{2}{*}{ Período } & \multicolumn{4}{|c|}{ Cenário } \\
\hline & & & 1 & 2 & 3 & 4 \\
\hline \multirow{5}{*}{ Qtde. transportada $X T_{\text {"PA11" } t}^{\text {"granel"' granel" }}$} & ton & 1 & - & - & - & - \\
\hline & ton & 2 & - & - & - & - \\
\hline & ton & 3 & - & - & - & - \\
\hline & ton & 4 & - & - & - & - \\
\hline & ton & 5 & - & - & - & - \\
\hline \multirow{5}{*}{ Qtde. transportada $X T_{\text {"PAl1" } t}^{\text {"tambor"'tambor" }}$} & ton & 1 & - & - & - & - \\
\hline & ton & 2 & - & - & - & - \\
\hline & ton & 3 & - & - & - & - \\
\hline & ton & 4 & - & - & - & - \\
\hline & ton & 5 & 100 & 100 & 100 & 100 \\
\hline \multirow{5}{*}{ Qtde. transportada $X T_{\text {"PA12" } t}^{\text {"granel"' granel" }}$} & ton & 1 & - & - & - & - \\
\hline & ton & 2 & - & - & - & - \\
\hline & ton & 3 & - & - & - & - \\
\hline & ton & 4 & - & - & - & - \\
\hline & ton & 5 & 330 & 330 & 330 & 330 \\
\hline \multirow{5}{*}{ Qtde. transportada $X T_{\text {"PA12" } t}^{\text {"tambor"'tambor" }}$} & ton & 1 & - & - & - & - \\
\hline & ton & 2 & - & - & - & - \\
\hline & ton & 3 & - & - & - & - \\
\hline & ton & 4 & - & - & - & - \\
\hline & ton & 5 & - & - & - & - \\
\hline \multirow{5}{*}{ Qtde. transportada $X T_{\text {"PA13" } t}^{\text {"granel"' granel" }}$} & ton & 1 & - & - & - & - \\
\hline & ton & 2 & - & - & - & - \\
\hline & ton & 3 & - & - & 70 & 70 \\
\hline & ton & 4 & - & - & 290 & 130 \\
\hline & ton & 5 & 440 & 440 & 80 & 240 \\
\hline \multirow{5}{*}{ Qtde. transportada $X T_{\text {"PA13"t }}^{\text {"tambor"'tambor" }}$} & ton & 1 & - & - & - & - \\
\hline & ton & 2 & - & - & - & - \\
\hline & ton & 3 & - & - & - & - \\
\hline & ton & 4 & - & - & - & 60 \\
\hline & ton & 5 & - & - & - & - \\
\hline
\end{tabular}

ao modelo de distribuição, permitimos a antecipação da produção de produtos para, em seguida, enviá-los aos estoques externos.

\section{Cenário 4}

Para avaliar como o modelo se comporta quando o volume de produção excede a capacidade total de armazenagem a granel, reduziu-se a capacidade de estocagem nos tank farms externos de 1650 para 200 toneladas (tabela 9). Nesta nova configuração, o modelo, no terceiro período, esbarra na restrição de capacidade de estocagem nos tank farms da fábrica (tabela 12). Assim, fez-se necessário efetuar a mistura e transporte de produto para os tank farms externos (tabelas 10 e 11, respectivamente). No entanto, no quarto período a capacidade de 
Tabela 12 - Resultados: estoques de produtos na fábrica $\sum_{p} E P F_{p t}^{k}$ e externo $\sum_{p} E P E_{p t}^{l}$ (em toneladas), no final de cada período nos 4 cenários

\begin{tabular}{|c|c|c|c|c|c|}
\hline \multirow{2}{*}{ Variável } & \multirow{2}{*}{ Período } & \multicolumn{4}{|c|}{ Cenário } \\
\hline & & 1 & 2 & 3 & 4 \\
\hline \multirow{5}{*}{ Fab.: $\sum_{p} E P F_{p t}^{\prime \text { granel }^{\prime \prime}}+\sum_{j} E B_{j t}$} & 1 & 290 & 290 & 290 & 290 \\
\hline & 2 & 580 & 580 & 580 & 580 \\
\hline & 3 & 870 & 870 & 800 & 800 \\
\hline & 4 & 1.160 & 1.160 & 800 & 800 \\
\hline & 5 & 290 & 290 & 290 & 230 \\
\hline \multirow{5}{*}{ Ext:: $\sum_{p} E P E_{p t}^{\prime \text { granel }^{\prime \prime}}$} & 1 & - & - & - & - \\
\hline & 2 & - & - & - & - \\
\hline & 3 & - & - & 70 & 70 \\
\hline & 4 & - & - & 360 & 200 \\
\hline & 5 & - & - & - & - \\
\hline \multirow{5}{*}{ Fab.: $\sum_{p} E P F_{p t}^{\text {"tambor" }}$} & 1 & - & - & - & - \\
\hline & 2 & - & - & - & - \\
\hline & 3 & - & - & - & - \\
\hline & 4 & - & - & - & - \\
\hline & 5 & - & - & - & - \\
\hline \multirow{5}{*}{ Ext.: $\sum_{p} E P E_{p t}^{\prime \prime t a m b o r "}$} & 1 & - & - & - & - \\
\hline & 2 & - & - & - & - \\
\hline & 3 & - & - & - & - \\
\hline & 4 & - & - & - & 160 \\
\hline & 5 & - & - & - & 60 \\
\hline
\end{tabular}

armazenagem a granel da fábrica e fora dela esgotou-se (tabela 12). Deste modo, o modelo determinou o entamboramento do excedente de produção (tabela 10). Com isto, o custo total do sistema cresce 695 u.m. em relação ao cenário 3 (de 3029 para 3724 u.m., conforme tabela 10), em função da necessidade de entamborar, transportar e estocar a produção excedente, além do custo financeiro desta operação.

\section{Outros cenários}

Vários outros cenários foram explorados a partir do cenário 4, como por exemplo:

- Aumentou-se a porcentagem de adição de base tipo "Hamlin", de 10\% para $20 \%$. Como resposta, o modelo corretamente retornou que o problema é infactível.
- Aumentou-se a capacidade de armazenagem em tambores nas câmaras frias da fábrica de 0 para 60 toneladas. A resposta do modelo foi deixar de transportar o excedente entamborado (60 toneladas), das câmaras frias da fábrica para as câmaras frias externas, gerando economias com transporte e armazenamento. O custo total deste cenário foi de 3558 u.m.

- Alterou-se o estoque inicial do produto "PA12" (granel) de 0 para 100 toneladas. A resposta do modelo foi reduzir a produção deste produto em 100 toneladas, e aumentar o entamboramento em outras 100 toneladas de "PA13" (tambor), este último, devido à falta de espaço físico para armazenagem a granel. O custo total deste cenário foi de 4870 u.m. 
Tabela 13 - Ratios obtidos pelo modelo (1)-(11) (coluna "antes") e pelo modelo (2)-(14) (coluna "depois") para o cenário 4

\begin{tabular}{|c|c|c|c|c|c|c|c|c|c|c|c|c|c|}
\hline \multirow{4}{*}{$\begin{array}{c}\text { Produto } \\
p\end{array}$} & \multirow{4}{*}{$\begin{array}{l}\text { Meta } \\
\text { p/ ratio }\end{array}$} & \multicolumn{12}{|c|}{ Resultados } \\
\hline & & \multicolumn{6}{|c|}{ Antes } & \multicolumn{6}{|c|}{ Depois } \\
\hline & & \multicolumn{2}{|c|}{ Período 3} & \multicolumn{2}{|c|}{ Período 4} & \multicolumn{2}{|c|}{ Período 5} & \multicolumn{2}{|c|}{ Período 3} & \multicolumn{2}{|c|}{ Período 4} & \multicolumn{2}{|c|}{ Período 5} \\
\hline & & $\begin{array}{l}\text { Qtde } \\
\text { (ton) }\end{array}$ & Ratio & $\begin{array}{l}\text { Qtde } \\
\text { (ton) }\end{array}$ & Ratio & $\begin{array}{l}\text { Qtde } \\
\text { (ton) }\end{array}$ & Ratio & $\begin{array}{l}\text { Qtde } \\
\text { (ton) }\end{array}$ & Ratio & $\begin{array}{l}\text { Qtde } \\
\text { (ton) }\end{array}$ & Ratio & $\begin{array}{l}\text { Qtde } \\
\text { (ton) }\end{array}$ & Ratio \\
\hline$P A R 11$ em tambor & 11.5 & - & - & 100 & 11.2 & - & - & - & - & 100 & 11.9 & - & - \\
\hline$P A R 12$ a granel & 12.5 & - & - & 144 & 12.9 & 186 & 12.9 & - & - & 38 & 12.5 & 292 & 12.5 \\
\hline$P A R 13$ a granel & 13.5 & 70 & 13.9 & 264 & 13.1 & 106 & 13.9 & 70 & 13.5 & 370 & 13.5 & - & - \\
\hline$P A R 13$ em tambor & 13.5 & - & - & 60 & 13.1 & - & - & - & - & 60 & 13.5 & - & - \\
\hline
\end{tabular}

Com base nos resultados obtidos nessa seção, observamos que o modelo é consistente e reflete satisfatoriamente o comportamento esperado do sistema em estudo ao se perturbar determinados parâmetros.

\subsection{Avaliação do modelo de programação de metas}

Para analisar o modelo de programação de metas (2)-(14), utilizou-se arbitrariamente o cenário 4. Primeiramente, resolveu-se o modelo (2)-(14) considerando-se apenas a meta 1 na função objetivo (12), o que, como era esperado, resultou na mesma solução de custo mínimo do modelo (1)-(11), com valor $s_{1}^{+}=F^{*}=3724$ u.m. (conforme tabela 10). Em seguida, resolveu-se o modelo (2)-(14) considerando-se apenas a meta 2 na função objetivo (12) e incluindo-se a restrição $S_{1}^{+}=F^{*}$ (conforme discussão na seção 3.2), o que resultou na solução de desvio mínimo dos valores médios das especificações de ratio de cada produto, com valor $\sum_{t} \sum_{k} \sum_{p}\left(s_{2 p t}^{k+}+s_{2 p t}^{k-}\right)=40,5$.

Note que este desvio é bem menor do que o desvio de 224,0 da solução de custo mínimo do modelo (1)-(11). A tabela 13 apresenta as quantidades e os ratios dos produtos produzidos nos períodos 3, 4 e 5 para a solução do modelo
(1)-(11) (coluna "antes" da tabela 13) e a solução do modelo (2)-(14) (coluna "depois"). Observe que, para o mesmo valor da meta 1 (custo total), o modelo (2)-(14) apresentou benefícios significativos do ponto de vista da meta $2 \mathrm{em}$ relação ao modelo (1)-(11), o que justifica sua utilização.

\section{Conclusões e Perspectivas}

$\mathrm{C}$ om base nos resultados obtidos na seção 4, verifica-se que os modelos aqui apresentados, baseados em programação linear e programação de metas, se comportam de maneira satisfatória para representar o problema em estudo. Observa-se que é importante agregar o plano de mistura ao plano de distribuição, uma vez que isto permite a antecipação da produção de sucos na fábrica e imediata estocagem fora da fábrica (conforme discutido, por exemplo, no cenário 3 da seção 4.1), obtendo-se assim uma ferramenta efetiva para a análise de custos e o planejamento dessas atividades. Convém salientar que a metodologia utilizada no trabalho, baseada em programação linear, programação de metas e na linguagem de modelagem GAMS, é acessível para aplicações empresariais.

Uma perspectiva importante para pesquisa futura é aplicar os modelos em uma situação real de uma safra, e comparar as soluções obtidas 
pelos modelos com as adotadas pela empresa. Apesar das dificuldades deste experimento, principalmente com respeito à compilação e análise de dados, pretendemos realizá-lo num futuro próximo na própria Citrovita. Outra possível pesquisa futura bem mais trabalhosa que a anterior seria integrar, no presente modelo de mistura e distribuição de suco, um modelo de planejamento de colheita de laranja, o que geraria um poderoso instrumento para análise de decisões táticas e estratégicas, desde a colheita da laranja no campo, até a colocação do produto final em navios para exportação.

\section{Agradecimentos}

Os autores agradecem a Candido Shigueyuqui Hotta, Gerente Geral Industrial da Citrovita, e Otto L. Azevedo Barreto, Gerente Industrial da Citrovita, pelo apoio a presente pesquisa. Também agradecem aos três revisores anônimos pelos úteis comentários e sugestões.

\section{Referências Bibliográficas}

ACKOFF, R.L.: Scientific Method: optimizing applied research decisions. John Wiley \& Sons, Inc., 1962.

AL-SHAMMARI, M. \& DAWOOD, I.: "Linear Programming Applied to a Production Blending Problem: A Spreadsheet Modeling Approach." Production and Inventory Management Journal, v. 38, n. 1, p. 1-7, 1997.

BALLOU, R.H.: Business Logistics Management. Prentice-Hall, Inc., 1992.

BAZARAA, M.S.; JARVIS, J.J. \& SHERALI, H.D.: Linear Programming and Network Flows. John Wiley \& Sons, Inc., 1990.

BROOKE, A.; KENDRICK, D.; MEERAUS, A. \& ROSENTHAL, R.E.: GAMS: A User's Guide, Release 2.25, The Scientific Press, 1992.

F.A.O. (Food and Agriculture Organization of the United Nations): Oranges Production. Fonte: $<$ http://apps.fao.org/lim500/nph-wrap.pl?Production. Crops.Primary\&Domain $=$ SUA\&servlet $=1>$, impresso em 01/02/2000.

F.A.O. (Food and Agriculture Organization of the United Nations): Orange Juice Concentrated Exports. Fonte: <http://apps.fao.org/lim500/nphwrap.pl?Trade.CropslivestockProduct\&Domain= SUA\&servlet=1>, impresso em 02/02/2000.

FERNANDES, F. \& MORABITO, R.: "Linguagens de Modelagem GAMS e LINGO: Aplicação a um Problema de Balanceamento de Linha de Montagem." Cadernos DEP, n. 20, p. 8-28, Universidade Federal de São Carlos, 1993.

HAX, A.C. \& CANDEA, D.: Production and Inventory Management. Prentice-Hall, Inc., 1984.
HILLIER, F.S. \& LIEBERMAN, G.J.: Introdução à Pesquisa Operacional. Editora Campus Ltda. I São Paulo: Editora da Universidade de São Paulo, 1988.

JOHNSON, L.A. \& MONTGOMERY, D.C.: Operations Research in Production Planning, Scheduling, and Inventory Control. John Wiley \& Sons, Inc., 1974.

KESTERSON, J.W. \& BRADDOCK, R.J.: "By-Products and Specialty Products of Florida Citrus." Institute of Food and Agricultutal Sciences, University of Florida, Gainesville, Bulletin 784, 1976.

MUNHOZ, J.R.: Um Modelo Baseado em Programação Linear e Programação de Metas para Análise de um Sistema de Produção $e$ Distribuição de Suco Concentrado Congelado de Laranja. Dissertação de Mestrado, Departamento de Engenharia de Produção - Universidade Federal de São Carlos, 2000.

NAHMIAS, S.: Production and Operations Analysis. Richard D. Irwin, Inc., 1993.

OZAN, T.M.: Applied Mathematical Programming for Engineering and Production Management. Prentice-Hall, Inc., 1986.

PINTO, K.C.R.: Contribuição à Análise de Decisão sobre os Sistemas de Distribuição Física de Suco de Laranja Brasileiro de Exportação. Tese de Doutorado, Escola de Engenharia de São Carlos Universidade de São Paulo, 1996.

SCHRAGE, L.: Linear, Integer and Quadratic Programming with LINDO. The Scientific Press, 1986. 
SHAPIRO, J.F.: "Mathematical Programming Models and Methods for Production Planning and Scheduling." Em: GRAVES, S.C., RINNOOY KAN, A.H.G. and ZIPKIN, P.H. (editors): Logistics of Production and Inventory (Handbooks in Operations Research and Management Science: v.4), Elsevier Science Publishers B.V., p. 371-439, 1993.

VIEGAS, F.C.P.; STEGER, E.; ANTONIO, A.P.; FOX, K.I. \& GRAY, L.E.: "Processamento dos Produtos Cítricos com Máquinas FMC'. Apostila do curso "Processamento de Laranja com Máquinas FMC”, Araraquara-SP, FMC do Brasil S.A., 1983.
WIIG, K.M.: "Petroleum Product Distribution Planning by Linear Programming." Em: SALKIN, H.M. and SAHA, J. (editors): Studies in Linear Programming (Studies in Management Science and Systems: v.2), North-Holland Publishing Company, p. 74-91, 1975.

WILLIAMS, H.P.: Model Building in Mathematical Programming. John Wiley \& Sons, Ltd., 1978.

WINSTON, W.L.: Operations Research: Applications and Algorithms. Wadsworth, Inc., 1991.

\title{
A MODEL BASED ON LINEAR PROGRAMMING AND GOAL PROGRAMMING TO ANALYZE A FROZEN CONCENTRATED ORANGE JUICE PRODUCTION AND DISTRIBUTION SYSTEM
}

\begin{abstract}
This work proposes a model based on linear programming and goal programming to support decisions in the blending process and distribution of frozen concentrated orange juice. This study explores the importance of blending decisions for the logistic analysis of the orange juice distribution, besides transportation and storage decisions. The model utilizes well-known concepts from the literature of blending problems and multistage, multiproduct and multiperiod production planning problems, and it was solved using the GAMS (General Algebraic Modeling System) programming language. A case study was developed in an orange juice industry located in São Paulo State, and the preliminary results are promising.
\end{abstract}

Key words: linear programming, goal programming, blending process, logistics of distribution, orange juice, multistage, multiproducts and multiperiods production planning. 